\title{
Social responsibility during the COVID-19 pandemic: Tobacco industry's trojan horse in Europe
}

\author{
Charis Girvalaki',2, Enkeleint A. Mechili1,2,3, Cornel R. Loghin', Filippos T. Filippidis ${ }^{4}$
}

Smoking causes more than 8 million deaths every year ${ }^{1}$. Recent studies suggest that smokers suffer more severely and have worse outcomes from COVID-19², highlighting that evidence-based practices to support patients to quit smoking should be a public health priority ${ }^{1}$. COVID-19 may be an emergency, however we should not suspend our vigilance against Tobacco Industry's (TI) subversive tactics used to improve its image through corporate social responsibility activities ${ }^{4}$. To identify any 'goodwill' tactics or new TI campaigns promoting 'safer' products during the pandemic, the European Network for Smoking and Tobacco Prevention (ENSP) distributed an online questionnaire among its members around Europe. Responses were received from 22 countries, 14 (63.6\%) of which reported some kind of country-specific TI interference during the pandemic.

The potential development of a tobacco-leaves-based vaccine against COVID-19 by British American Tobacco (BAT) has been widely covered by media globally, with ENSP members reporting extensive coverage in Belgium, France, Georgia, Greece, Lithuania, Romania, Spain the Netherlands, and the UK. Similarly, pre-prints of studies claiming that nicotine is protective against COVID- $19^{5}$, received disproportionately wide media attention in many countries.

Targeted and country-specific TI activities during the pandemic include: In Bulgaria, Philip Morris (PM) Bulgaria (BG) donated BGN 320000 (EUR $150000)$ to the BCause Foundation to fight COVID-19. Media coverage of this donation were accompanied by articles praising the leadership of Philip Morris International (PMI) and PM BG with regard to Heated Tobacco Products (HTPs). PM BG also supported the popular artistic ArtAction initiative.

In France, BAT and PMI have also tried to sponsor or offer financial aid to communities or bodies mobilized to fight against COVID-19.

In Georgia, PMI, BAT and Japan Tobacco International (JTI) donated around USD 30000 each to the special Governmental Fund 'StopCov' while BAT distributed face shields to 300 journalists and 500 emergency service workers.

In Greece, the subsidiary of PMI 'Papastratos' and the Greek TI Karelia donated 50 ventilators each to the Greek healthcare system.

In Italy, PMI donated EUR 1000000 to the Civil Protection for medical supplies, medical equipment and first aid goods and launched the campaign \#DueVoltePiùVicini (\#TwoTimeCloser) to raise additional funds with a commitment to double donations by their employees, tobacconists and consumers registered with IQOS Club.

In Lithuania, PM Baltic donated EUR 110000 to a COVID-19 relief fund, headed by the former president of Lithuania, Dalia Grybauskaitè, which is illegal in the country. In addition, PM Lithuania announced that they are providing food for people in need in Klaipeda municipality in cooperation with the Klaipeda municipal social services center.
AFFILIATION

1 European Network for Smoking and Tobacco Prevention, Brussels, Belgium

2 Medical School, University of Crete, Heraklion, Greece

3 Department of Healthcare, Faculty of Public Health, University of Vlora, Vlora, Albania

4 Department of Primary Care and Public Health, Imperial College London, London, United Kingdom

CORRESPONDENCE TO Charis Girvalaki. European Network for Smoking and Tobacco Prevention, Brussels, Belgium. E-mail: charis@tobcontrol.eu ORCID ID: https://orcid.org/00000001-6849-0972

KEYWORDS

tobacco industry interference, COVID-19, pandemic, Europe

Received: 31 May 2020 Accepted: 1 June 2020 
In Romania, PMI donated USD 1000000 to the Romanian Red Cross Affiliate to purchase ventilators, medical and protective equipment. Additionally, Daruieste Viata, a major Romanian NGO, received support to produce a video tutorial on washing hands, featuring various celebrities, branded with IQOS's Creative Hub in Romania (Qreator by IQOS). Ahead of the deadline of 20 May when menthol cigarettes would be removed from the EU market, online campaigns by BAT and PMI to push consumers towards HTP's, still available in menthol versions, have intensified.

In Switzerland, BAT offered to provide free smokeless tobacco products to members of the Swiss army currently deployed around the country.

In Turkey, PMI and JTI made donations to the national COVID-19 help campaign (USD 675000 and USD 180000 respectively).

Although many physical shops were closed, online sales continued across Europe offering free delivery (e.g. in Cyprus, Romania, and Ukraine), while TI activities in all countries have been heavily promoted by a number of traditional and social media.

All the above reveal a series of deliberate tactics through which TI is exploiting media attention to improve their corporate profile, break down opposition, present themselves as socially responsible enterprises, engage with governments and promote products such HTPs or even attempt to renormalize tobacco consumption.

We recognize that governments around the world are fighting the pandemic with limited resources and in the face of a major recession any support may be valuable. However, we are urging them to uphold their commitment to Article 5.3 of the World Health Organization Framework Convention on Tobacco Control which requires governments to take measures to protect health policy 'from commercial and other vested interests of the tobacco industry' ${ }^{\prime}$, while supporting smoking cessation. Any other action would jeopardize their capacity and credibility to protect their people from a leading cause of death, which is also associated with more severe outcomes of COVID-193,7. Civil society, media and the entire public health community should remain alert and contribute to protecting population health. Continued tobacco use is likely to kill many times more people than the current pandemic, which only shows the devastating impact of smoking in European countries and globally ${ }^{1}$.

\section{REFERENCES}

1. World Health Organization. WHO Report on the Global Tobacco Epidemic, 2019: Offer help to quit tobacco use. The MPOWER package. https://apps.who.int/iris/bitstream/handle/10665/326043/9789241516204-eng.pdf?ua=1. Accessed May 4, 2020.

2. Mehra M, Desai S, Kuy SR, Henry T, Patel A. Cardiovascular disease, drug therapy, and mortality in Covid-19. N Engl J Med. 2020. doi:10.1056/NEJMoa2007621

3. Vardavas CI, Nikitara K. COVID-19 and smoking: A systematic review of the evidence. Tob Induc Dis. 2020;18(March). doi:10.18332/tid/119324

4. Global Center for Good Governance in Tobacco Control. Tobacco Industry's COVID Donations vs Economic Cost of Tobacco. https://ggtc.world/2020/04/23/tobacco-industrys-covid-donations-vs-economic-cost-of-tobacco/. Published April 23, 2020. Accessed May 4, 2020.

5. Changeux JP, Amoura Z, Rey F, Miyara M. A nicotinic hypothesis for Covid-19 with preventive and therapeutic implications. Qeios. 2020. doi:10.32388/FXGQSB

6. World Health Organization. Guidelines for implementation of article 5.3 of the WHO Framework Convention on Tobacco Control. http://www.who. int/fctc/guidelines/article_5_3.pdf. Published 2008. Accessed May 4, 2020.

7. Guan W, Ni Z, Hu Y, et al. Clinical characteristics of coronavirus disease 2019 in China. N Engl J Med. 2020;382(18)1708-1720. doi:10.1056/NEJMoa2002032

CONFLICTS OF INTEREST

The authors have completed and submitted the ICMJE Form for Disclosure of Potential Conflicts of Interest and none was reported.

FUNDING

There was no source of funding for this research.

PROVENANCE AND PEER REVIEW

Not commissioned; internally peer reviewed. 